\title{
UMA REVISÃO GERAL SOBRE O CLIMA DA AMAZÔNIA
}

\author{
Gilberto FISCH', José A. MARENGO'2, Carlos A. NOBRE
}

RESUMO - Este trabalho busca apresentar, de uma maneira compacta, os principais resultados cientificos já alcançados pela comunidade brasileira e mundial sobre pesquisas na Amazỏnia. Aborda-se o paleoclima da região, bem como as características atuais, em termos de temperatura do ar e da distribuição de chuvas. São discutidos os principais sistemas atmosféricos atuantes na região, tais como linhas de instabilidade, brisa fluvial, teleconexões com El-Niño, interação com sistemas frontais no sul do pais, friagens, além da variabilidade do clima nas escalas interanuais e de longo-prazo. Tendo em vista as altas taxas de desmatamento em algumas partes da Amazonia, são discutidos as principais modificaçôes microclimáticas e resultados obtidos por simulações numéricas devido à substituição de floresta tropical por áreas de pastagens. Finalizando, é apresentado um resumo dos vários experimentos micrometeorológicos que ocorreram na Amazônia nas últimas duas décadas.

Palavras-chave: Amazónia, simulação climática, sistemas atmosféricos, experimentos micrometeorológicos,

\section{The Climate of Amazonia - A Review}

ABSTRACT - This paper describes recent research on some climatic aspects of Amazonia. It describes the paleoclimate, characteristics of the present patterns of air temperature and rainfall distribution, together with results from field observations of atmospheric phenomena (squall lines, the Bolivian upper-tropospheric high, river breezes, relations with El Niño, interactions with polar fronts and convection processes, cold spells, inter-annual and longer-term variability). Since deforestation is proceeding rapidly in Amazonia, the paper describes the principal changes in microclimate that result from it and the results of numeric simulations in which tropical forest is replaced by pasture. The paper concludes with a summary of micrometeorological studies conducted in Amazonia over the last two decades.

Key-words: Amazon region, climatic simulation, atmospheric system, micrometeorological experiments.

\section{INTRODUÇÃO}

A Bacia Amazônica possui uma área estimada de 6,3 milhões de quilometros quadrados, sendo que aproximadamente 5 milhões em território brasileiro e o restante divido entre os países da Bolívia, Colômbia, Equador e Peru. Esta região é limitada à oeste pela Cordilheira dos Andes (com elevações de até $6.000 \mathrm{~m}$ ), à norte pelo Planalto das Guianas (com picos montanhosos de até $3.000 \mathrm{~m}$ ), ao sul pelo Planalto Central (altitudes típicas de $1.200 \mathrm{~m}$ ) e à leste pelo Oceano Atlântico, por onde toda a água captada na bacia escoa para o mar. Segundo o IBGE, a área da Amazônia Legal no Brasil é de $5.032 .925 \mathrm{~km}^{2}$, compreendidos pelos estados do Pará, Amazonas, Rondônia, Roraima, Acre e Amapá e parte dos territórios do Tocantins, Mato Grosso e Maranhão. Imagens de satélites analisadas pelo INPE estimam em $126.000 \mathrm{~km}^{2}$ a área já desmatada até 1991, com uma taxa de desmatamento anual de $21.000 \mathrm{~km}^{2}$. ano ${ }^{-1}$, durante o

1 Centro Téenico Aeroespacial (CTA/IAE-ACA), São José dos Campos, 12228-904, SP, Brasil. (gfisch@aca.iae.cta.br)

2 Centro de Previsão de Tempo e Estudos Climáticos (CPTEC/INPE), Cachoeira Paulista, 12630000, SP, Brasil. 
período de 1978-1989, decrescendo este valor para $11.130 \mathrm{~km}^{2}$.ano-1 durante os anos de 1990-1991 (INPE, 1992). As regiōes que mais sofreram com o desmatamento são as partes Sul e Leste do Pará (após a construção da rodovia Belém-Brasília) e as partes Norte do Mato Grosso e Sul de Rondônia (devido à rodovia Cuiabá-Porto Velho).

A convecção na região amazônica é um importante mecanismo de aquecimento da atmosfera tropical e sua variação, em termos de intensidade $\mathrm{e}$ posição, possue um papel importante na determinação do tempo e clima desta região. A liberação de calor durante a época chuvosa é tipicamente de $2,5 \mathrm{~K}$. ia $^{-1}$ (Figueroa \& Nobre, 1990), o equivalente à uma precipitação de $10 \mathrm{~mm} \cdot$ dia $^{-1}$.

Molion (1987; 1993) estudou as circulações de macro e meso-escala que atuam na Amazônia e os processos dinâmicos que organizam e promovem a precipitação naquela área. Segundo este autor, os mecanismos que provocam chuva na Amazônia podem ser agrupados em 3 tipos:

a) convecção diurna resultante do aquecimento da superfície e condições de larga-escala favoráveis;

b) linhas de instabilidade originadas na costa N-NE do litoral do Atlântico;

c) aglomerados convectivos de meso e larga escala, associados com a penetração de sistemas frontais na região S/SE do Brasil e interagindo com a região Amazônica;

Sendo assim, a nebulosidade e o regime de precipitação determinam o clima amazônico, sendo que suas características são o resultado de um complexo sistema de interações de fenômenos meteorológicos.

Este trabalho aborda vários aspectos que caracterizam e determinam o clima da região amazônica. Na seção 2, descreve-se o paleoclima amazônico com base em dados obtidos por estudos geomorfológicos e palinológicos. A descrição geral do clima é realizada na seção 3 , ao passo que os principais sistemas e fenômenos meteorológicos atuantes nesta região são analisados na seção 4. Resultados de estudos sobre variabilidade e mudança climática na Amazônia são mostrados na seção 5 . Um resumo dos principais resultados micrometeorológicos de áreas de floresta e desmatadas (pastagens) são apresentados na seção 6 , sendo que resultados de simulações climáticas do efeito do desmatamento encontram-se na seção 7. Uma descrição suscinta dos principais experimentos realizados a partir dos anos 80 é mostrado na seção 8. Este trabalho busca apresentar, de uma maneira compacta, os principais resultados científícos já alcançados pela comunidade brasileira e regional sobre pesquisas na Amazônia.

\section{PALEOCLIMATOLOGIA}

A Amazônia situa-se na região equatorial e possui um clima quente $\mathrm{e}$ úmido, embora este comportamento não tenha sido uma constância durante os últimos 15.000 anos. Alterações da relação Terra-Sol provocaram mudanças significativas na quantidade de energia solar recebida pelo planeta Terra, modificando a composição dos sistemas atmosféricos predominantes e, consequentemente, o clima. A menor insolação provocou movimentos do 
anti-ciclone do Atlântico Sul e correntes oceânicas frias (corrente das Malvinas) em direção ao Equador. Com o resfriamento da temperatura do Oceano Atlântico, os ventos alíseos penetraram no continente com menos umidade, provocando uma aumento da região de aridez. As principais mudanças climáticas e fitográficas ocorridas durante o período quaternário foram resultados de frequentes alterações interglaciais e glaciais, as quais produziam mudanças bruscas, tais como a troca de vegetação predominante de floresta para savanas, durante períodos de clima mais frio e seco (glacial). Observações de pólen (Absy, 1985) encontradas em sedimentos indicam que, durante parte do Holoceno (entre 5.000 e 3.000 anos passados), grandes áreas de savanas existiam na Amazônia, aonde atualmente existe floresta. Associado à este resfriamento, ocorreu o abaixamento do nivel dos mares, com consequências na quantidade de água na Bacia Amazônica. Diagramas de pólen indicam que também não havia floresta ao final do Pleistoceno (aproximadamente 11.500 anos passados). Entre os anos de 4.000 e 2.100 antes do presente e ao redor do ano de 700 (1.200 DC), Absy (1985) sugere que ocorreram grandes variações de precipitação na região Amazônica, causando o abaixamento (e em alguns casos secamento) de rios amazônicos, com mudanças significativas na fauna e flora.

\section{Climatologia}

O clima atual da região amazônica é uma combinação de vários fatores, sendo que o mais importante é a disponibilidade de energia solar, através do balanço de energia. A Amazônia, situada na região entre $5^{\circ} \mathrm{N}$ e $10^{\circ} \mathrm{S}$ recebe no topo da atmosfera um valor máximo de $36,7 \mathrm{MJ} \cdot \mathrm{m}^{-2} \cdot \mathrm{dia}^{-1} \mathrm{em}$ Dezembro/Janeiro e um valor mínimo de 30,7 MJ.m-2. $\mathrm{dia}^{-1}$ em Junho/Julho (Salati \& Marques, 1984). Estes valores são reduzidos pela transmissão atmoférica mas são, em média, da ordem de 16-18 MJ.m.2. dia ${ }^{-1}$ para valores de radiação solar incidente à superfície. Medidas realizadas na Amazônia Central (Manaus-AM) indicam que os maiores totais de radiação que chegam na superfície ocorrem nos meses de Setembro/ Outubro, sendo que os mínimos são nos meses de Dezembro à Fevereiro. Esta distribuição é controlada pela nebulosidade advinda da migração SE/NW da convecção amazônica (Horel et al., 1989). Feitosa et al. (1997), através de um conjunto de 3 anos de dados horários da energia solar, estudaram o comportamento médio da energia solar na área de Rondônia (RO), encontrando valores integrados da radiação solar ao longo do dia de $18,3 \mathrm{MJ} \cdot \mathrm{m}^{-2} \cdot \mathrm{dia}^{-1}$ para a estação seca e de $17,1 \mathrm{MJ} \cdot \mathrm{m}^{-2}$.dia ${ }^{-1}$ na estação chuvosa. Neste mesmo artigo, os autores comparam a influência da superfície (floresta tropical ou pastagem) na atenuação da radiação solar pela atmosfera, mostrando que os aerossóis produzidos por fumaça de queimadas produzem uma transmissividade de 0,58 na pastagem contra valores de 0,66 em áreas de floresta, durante a estação seca. Durante a estação chuvosa, a radiação solar nas áreas de floresta e de pastagem são praticamente iguais 
(valores típicos de 17,0 MJ.m $\mathrm{m}^{-2} \cdot \mathrm{dia}^{-1}$ ).

Devido aos altos valores de energia que incide na superfície, o comportamento da temperatura do ar mostra uma pequena variação ao longo do ano, com excessão da parte mais ao sul (Rondônia e Mato Grosso), que inclusive sofre a ação de sistemas frontais (denominados localmente por Friagens - veja seção 4.3). A amplitude térmica sazonal é da ordem de $1-2^{\circ} \mathrm{C}$, sendo que os valores médios situam-se entre 24 e $26^{\circ} \mathrm{C}$. Especificamente, Belém (PA) apresenta a temperatura média mensal máxima de $26,5^{\circ} \mathrm{C}$ em Novembro e a minima temperatura de $25,4^{\circ} \mathrm{C}$ em Março. Por outro lado, Manaus (AM) possui seus extremos de temperatura nos meses de Setembro $\left(27,9^{\circ} \mathrm{C}\right)$ e Abril $\left(25,8^{\circ} \mathrm{C}\right)$. Salati \& Marques (1984) apresentam as médias mensais de 48 estações meteorológicas espalhadas pela Amazônia.

A energia que atinge a superficie terrestre é devolvida para a atmosfera na forma de fluxo de calor sensivel (aquecimento) e latente (evapotranspiraçâo). Desta forma, o balanço de energia e umidade interagem, sendo que o saldo de radiação é particionado em termos de calor sensivel e/ou latente, dependendo das condições ambientais e de água no solo.

A precipitação é um dos elementos climáticos mais importantes a ser analisado na região tropical, pois induz as características e comportamento dos outros, tais como temperatura, umidade relativa, ventos etc. Entretanto, a despeito da simplicidade de sua medida, é uma das variáveis meteorológicas mais difícies de serem medidas, uma vez que possue erros do tipo instrumental; de exposição e mesmo de localização (Molion \& Dallarosa, 1990). A região amazônica possui uma precipitação média de aproximadamente 2.300 mm.ano ${ }^{-1}$, embora na fronteira entre Brasil e Colômbia e Venezuela o total anual atinge $3.500 \mathrm{~mm}$. Nestas regiões não existe período de seca. Estes valores de precipitação elevada próximo à Cordilheira dos Andes devem-se à ascenção orográfica da umidade transportada pelos ventos alíseos de leste da Zona de Convergencia Inter-Tropical (ZCIT). Na região costeira (no litoral do Pará ao Amapá), a precipitação também é alta e sem período de seca definido, devido a influência das linhas de instabilidade que se formam ao longo da costa litorânea durante o periodo da tarde e que são forçadas pela brisa maritima. A distribuição espacial e temporal das chuvas na Amazônia foi detalhadamente estudada por Figueroa \& Nobre (1990), utilizando-se de 226 estações pluviométricas; por Marengo (1995), que usou dados de convecçâo (Radiação de Ondas Longas) do International Satellite Cloud Climatology Project (ISCCP) e também por Paiva \& Clarke (1995). O máximo da chuva na região central da Amazônia (próximo de $5^{\circ} \mathrm{S}$ ) pode estar associado com à penetração de sistemas frontais da região sul, interagindo e organizando a convecção local. A distribuição espacial e temporal da precipitação derivada por Figueroa \& Nobre (1990) é apresentada na Figura 1. O período de chuvas ou forte atividade convectiva na região amazônica é compreendido entre Novembro e Março, 


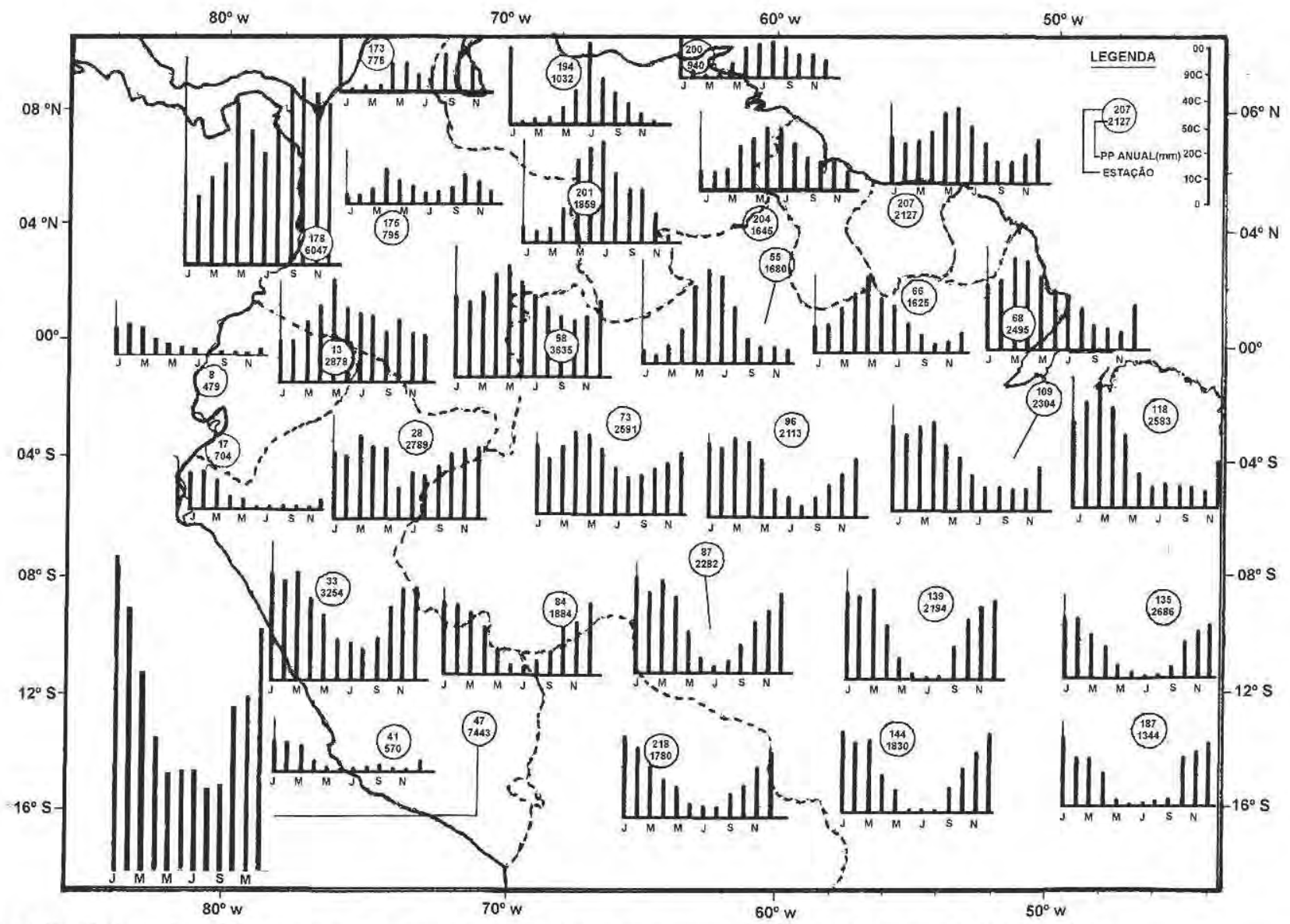


sendo que o período de seca (sem grande atividade convectiva) ocorre entre os meses de Maio e Setembro. Os meses de Abril e Outubro são meses de transição entre um regime e outro. A distribuição de chuva no trimestre Dezembro-Janeiro-Fevereiro (DJF) mostra uma região de precipitação alta (superior a $900 \mathrm{~mm}$ ) situada na parte oeste e central da Amazônia, em conexão com a posição geográfica da Alta da Bolívia. Por outro lado, no trimestre Junho-JulhoAgosto (JJA), o centro de máxima precipitação desloca-se para o norte e situa-se sobre a América Central. A região amazônica, principalmente na parte central, está sob o domínio do ramo descendente da Célula de Hadley, induzindo um periodo de seca bem característico. Este comportamente está completamente de acordo com o ciclo anual da atividade convectiva na região, conforme demonstrado por Horel et al. (1989). O ciclo diurno da precipitação na região tem sido menos estudado (por exemplo Paiva (1996) e Ferreira da Costa et al. (1997) mas os resultados obtidos mostram que, em áreas continentais, o periodo da tarde (entre $13-18$ horas) registra acima de $30 \%$ dos eventos de precipitação. Este comportamento é devido ao próprio ciclo de insolação e aquecimento da superfície. Em áreas próximas à grandes corpos d'águas, Molion \& Dallarosa (1990) mostraram que ocorre fenômenos de brisa fluvial, induzindo a formação de nuvens convectivas e precipitação (veja seção 4.5).

Um estudo climatológico da circulação troposférica sobre a região amazônica foi efetuado por Kousky \& Kagano (1981). Usando radiossondagens realizadas na Amazônia Central (Manaus, AM) e Oriental (Belém, PA) durante o periodo de 1968-1976, os autores encontraram que o vento em altos níveis $(200 \mathrm{hPa})$ é de oeste durante os meses de inverno (Junho à Agosto) nas duas localidades, embora a intensidade e ocorrência sejam variáveis. Este autores também sugerem que a distribuição de chuvas na Amazônia esteja relacionada com a posição da Alta da Bolívia. Em relação à água precipitável, esta é aproximadamente constante ao longo do ano, com pequeno decréscimo nos meses de sêca. Salati \& Marques (1984) apresentam os valores médios de água precipitável para Belém (PA) e Manaus (AM): 4,2 e 4,4 g. $\mathrm{cm}^{-2}$, com amplitude anual de 1,1 e 0,9 g. $\mathrm{cm}^{-2}$, respectivamente. Rao et al. (1996) também apresentam valores de água precipitável na região como sendo da ordem entre 4,0 e $5,5 \mathrm{~g} . \mathrm{cm}^{-2}$.

$\mathrm{O}$ balanço hídrico na região amazônica é difícil de ser calculado, devido a falta de continuidade espacial e temporal das medidas da precipitação, inexistência de medidas simultâneas de vazões fluviais, desconhecimento do armazenamento de água no solo etc. Entretanto, algumas tentativas de se entender melhor o regime hídrico dentro da bacia hidrográfica têm sido realizadas, através de várias técnicas, tais como o método climatonônico (Molion, 1975), balanço hidrico (Villa Nova et al., 1976), e aerológico (Marques et al., 1980; Rocha, 1991). Através de técnicas isotópicas da medida de concentração de 
oxigênio em água da chuva na região amazônica, Salati et al. (1979) determinaram que a precipitação na região é uma composição da quantidade de água evaporada localmente (evapotranspiração) adicionada de uma contribuição advinda do Oceano Atlântico. Desta maneira, podese estimar que $50 \%$ do vapor d'água que precipita pelas chuvas é gerado localmente (pela evapotranspiração), sendo o restante importado para a região pela fluxo atmosférico proveniente do Oceano Atlântico. A contribuição advinda do Oceano Pacífico é minima (Salati \& Vose, 1984). Marques et al. (1980) estimaram o balanço de água na Amazônia usando a divergência do fluxo de vapor d'água e obtiveram que $52 \%$ da precipitação na região entre Belém e Manaus é proveniente do Oceano Atlântico e o restante $(48 \%)$ é reciclado localmente Estes resultados coincidem com os de Salati et al. (1979). Em média, a precipitação da bacia é $12,0 \times 10^{12} \mathrm{~m}^{3}$.ano $\sigma^{-1}$, sendo que a descarga fluvial na foz do rio Amazonas é 5,5 x $10^{12} \mathrm{~m}^{3}$.ano-1 (Oltman, 1967). Como consequência do balanço, o resíduo (evapotranspiração) é de 6,5 x $10^{12} \mathrm{~m}^{3}$. ano ${ }^{-1}$ (Villa Nova et al., 1976). Em um outro estudo complementar à este, Salati \& Nobre (1991) separaram os vários componentes do balanço hidrico envolvidos na região amazônica e chegaram à um valor típico de 2.300 mm.ano ${ }^{-1}$ para a precipitação, sendo que a evapotranspiração local foi responsável por 1.200 mm.ano ${ }^{-1}$ e o escoamento superficial por $915 \mathrm{~mm} \cdot \mathrm{ano}^{-1}$. O fluxo de vapor d'água proveniente do Oceano Atlântico (input) foi de $1.350 \mathrm{~mm} \cdot \mathrm{mano}^{-1}$ e o fluxo de saída (output) para o Brasil Central foi de $585 \mathrm{~mm}^{-a n o^{-1}}$. O balanço hidrico da região também foi estudado por Matsuyama (1992) utilizando-se dados em pontos de grade do Centro de Previsão de Tempo Europeu (ECMWF) obtidos durante o período do experimento FGGE. Em seus cálculos para um ciclo sazonal completo, Matsuyama (1992) estimou a evapotranspiração, como resíduo do balanço hídrico, em 1.139,1 mm, que representa $53 \%$ da precipitação média na área de $2.152,6 \mathrm{~mm}$. O escoamento superficial foi calculado em $1.013,5 \mathrm{~mm}$, sendo a contribuição do fluxo atmosférico de $737,3 \mathrm{~mm}$. Estes valores são consistentes com as estimativas anteriores. Recentemente, Rao et al. (1996) usando também um conjunto de dados provenientes de previsões numéricas (no caso dados meteorológicos do ECMWF do periodo entre 1985-1989), confirmam que o fluxo de vapor d'água proveniente do oceano Atlântico é importante no ciclo hidrológico da região amazônica e que esta, por sua vez, também induz o campo de vapor d'água em grande parte do Brasil Central. Embora estes números apresentem incertezas muito grandes, eles são um primeiro balanço de como ocorre o ciclo hidrológico na região amazônica.

A evapotranspiração da floresta na região amazônica tem sido objeto de vários estudos (Villa Nova et al., 1976; Shuttleworth et al., 1987, entre outros), principalmente em casos da evapotranspiração potencial. As estimativas são de que a evapotranspiração potencial média seja entre 4,0-4,5 mm.dia ${ }^{-1}$, com variações sazonais decorrentes da existência ou nâo de chuvas. Salati \& Nobre (1991) apresentam um sumário de várias estimativas de evapotranspiração na 
região amazônica, no qual os vários métodos utilizados apresentaram valores médios anuais entre 3,6 e $5,2 \mathrm{~mm}^{-\mathrm{ano}^{-1}}$. Entretanto, poucas são as medidas ou estimativas da evapotranspiração real. Os estudos de Marques Filho et al. (1986) e Fisch (1990) com medidas comparativas entre a evapotranspiração real (medida com aparelhos de vórtices turbulentos) e estimativas da evapotranspiração potencial através de métodos diferentes (método de Penman-Monteith no caso de Fisch (1990) e da teoria da similaridade para Marques Filho et al. (1986)), chegaram a valores entre a razão das evapotranspirações real e potencial de 0,3 para Fisch (1990) e 0,4 para Marques Filho et al. (1986). Estes valores são típicos para a estação seca, sendo que, na época chuvosa, Shuttleworth et al. (1987) sugerem que a evapotranspiração real seja igual a potencial, uma vez que o solo possui muita umidade. Recentemente, Maia Alves (1997) analizou o ciclo sazonal da evapotranspiração real usando o modelo de Penman-Monteith e obteve valores entre 3,4 e $5,0 \mathrm{~mm} \cdot \mathrm{dia}^{-1}$ para a região de Ji-Paraná (RO). Estas análises foram obtidas com os dados provenientes do sitio experimental de floresta do Projeto ABRACOS.

\section{SISTEMAS ATMOSFÉRICOS ATUANTES NA REGIÃO AMAZÔNICA}

\section{1 - Circulação Geral e Alta da Bolívia}

A circulação geral da alta troposfera sobre a América do Sul tem sido bastante estudada nos últimos anos (Santos, 1986; Carvalho, 1989). Esta região possui uma característica muito particular de apresentar o desenvolvimento de um anti-ciclone em altos niveis ( $200 \mathrm{hPa})$, durante os meses de verão, associado com a forte convecção da região amazônica. Este anti-ciclone foi denominado de Alta da Bolivia $(\mathrm{AB})$, pois situa-se sobre a região do altiplano boliviano. Durante a época de inverno, ocorre a desintensificação da $\mathrm{AB}$, com o seu completo desaparecimento. A localização geográfica da $\mathrm{AB}$ possui variação intra-sazonal e inter-anual, associada a convecção na amazônia. Santos (1986) observou que, durante anos menos chuvosos na região amazônica, os centros da $\mathrm{AB}$ eram menos intensos. Analisando anos de ocorrência de El-Niño, Jones \& Horel (1990) reportam que, a AB localiza-se, em geral, à oeste de sua posição climatológica. Também foi observado por Carvalho (1989) que, para o evento do El-Niño 82-83, a atividade convectiva e precipitação na Amazônia diminuiu (veja seção 4.2), com a desintensificação da $\mathrm{AB}$. A manutenção deste centro quente anticiclonônico é devido à convergência, em baixos niveis, da umidade que vem de nordeste e de leste. Esta convergência provoca forte convecção, condensação e liberação de calor latente na média/alta troposfera, associada à atividade convectiva. Entretanto, esta atividade convectiva possui um ciclo anual de deslocamento na região amazônica (trimestre DJF - verão) para sobre a região da América Central. A investigação deste fenômeno pode ser efetuada pelas observações pluviométricas (Marengo, 1992) ou pela 
radiação de ondas longas (ROL), emitida pelo topo de nuvens e aglomerados convectivos (Horel et al., 1989; Marengo \& Hastenrath, 1993) e medidos por satélites meteorológicos de órbita polar. Já foi demonstrado que as observações de ROL estimam convenientemente a precipitação tropical (Carvalho, 1989). Segundo os resultados de Horel et al. (1989), a atividade convectiva sobre a América Tropical possui um deslocamento sazonal ao longo do eixo SE/NW, permanecendo aproximadamente 5 meses em cada hemisfério.

\section{2 - El - Niño}

O evento do El Niño/Oscilação Sul (ENOS) de 1982-1983 foi um dos mais intensos e afetou o tempo e clima da América do Sul de várias maneiras (Kayano \& Moura, 1986). No caso da região amazônica, este episódio provocou um período extremamente seco (Janeiro/Fevereiro) durante a estação chuvosa na Amazônia Central. O desvio da precipitação neste período (valor climatológico menos o valor observado de $82 / 83$ ), apresentou valores de até $-70 \%$ na área de Manaus (AM), com um valor menor na parte mais próxima do Oceano Atlântico ( $-20 \%$ em Belém). Este comportamento foi devido ao ramo descendente da célula de Walker deslocar-se para a região sobre a Amazônia, inibindo a formação de atividades convectivas (Nobre \& Rennó, 1985; Nobre \& Oliveira, 1987). Este periodo (Janeiro/Fevereiro $82 / 83$ ) foi caracterizado por possuir o menor indice pluviométrico nos últimos 50 anos. Em Manaus (AM), por exemplo, o total mensal de precipitação foi nulo, época em que a normal climatológica apresenta um valor superior à $300 \mathrm{~mm}$ (Nobre \& Oliveira, 1986). Em um estudo complementar à este, Kayano \& Moura (1986) analisaram a precipitação na América do Sul durante todo o evento do El Niño (junho de 1982 à agosto de 1983), indicando que a Amazônia sofreu um forte período de seca, com total de chuva de aproximadamente $50 \%$ menor que o valor climatológico. Devido a natureza heterogênea da precipitação e da localização de pluviômetros/pluviógrafos próximo aos rios (Molion \& Dallarosa, 1990), a medida da vazão de rios é uma medida robusta do ciclo hidrológico na área da Bacia, por representar a soma dos fenômenos hidrometeorológicos que ocorrem na área. Neste sentido, Molion \& Carvalho (1987) analisaram a descarga fluvial de rios na Amazônia e correlacionaram suas vazões com o evento ENOS $82 / 83$. Os resultados obtidos para os rios Trombetas e JiParaná indicaram que as correlações são positivas, sugerindo que o indice de oscilação sul possa ser um preditor da variabilidade de chuva nesta região. Richey et al. (1989) também mostraram que variabilidade inter-anual do regime de precipitação e descarga fluvial dos rios está associada com eventos de ENOS e possue escala de tempo de 2-3 anos.

Uma série de outros estudos também demonstraram os efeitos do evento ENOS na hidrologia da Amazônia. Aceituno (1988) mostrou 
uma tendência da diminuição de chuva na Amazônia do Norte, durante anos de El-Niño. Marengo (1991; 1992) mostrou que, em anos de El-Niño muito intenso como foram os anos de 1925-26, 1975-76 ou 1982-83, a precipitação do verão foi mais baixa que nos anos normais sobre a Amazônia do Norte, resultado este que também se observa nos níveis de água anormalmente baixos dos rios Negro e Amazonas. Estudos observacionais realizados por Marengo \& Hastenrath (1993), e que foram comprovados por estudos de modelagem do clima de Marengo et al. (1993), mostram que, durante anos de grande aquecimento das águas do Pacifico equatorial central (fenômeno do El-Niño), a ZCIT situa-se anomalamente mais ao norte do que sua posição normal sobre o Atlântico Tropical. Consequentemente os ventos aliseos de NE são mais fracos, reduzindo a umidade que penetra no interior da região amazônica. Sobre o lado oeste dos Andes, a convecção que produz as chuvas abundantes ao norte do Peru, provoca, por sua vez, movimentos de ar de subsidência compensatória no lado leste, contribuindo para uma menor quantidade de chuva na parte oeste da Amazônia.

\section{3 - Friagens}

Embora a região amazônica situe-se geograficamente próxima ao Equador, a parte meridional sofre, eventualmente, da ação de sistemas frontais, provocando o fenômeno localmente denominado de Friagem. $\mathrm{O}$ efeito destas invasões de ar polar na Amazônia tem sido pouco estudado e apenas os estudos de Brinkman \&
Ribeiro (1972), Hamilton \& Tarifa (1978), Marengo et al. (1997) e Fisch et al. (1997a) detalharam estes efeitos. Fisch et al. (1997a) realizaram uma estatística simples do número de eventos de Friagem na região da Amazônia durante os anos de 1992 e 1993 e obteve uma frequência de ocorrência de 7 casos por ano, durante os meses de Maio à Agosto. Brinkman \& Ribeiro (1972) citam que, no caso da Amazônia Central, ocorrem de 2 a 3 Friagens por ano, durante os meses de seca (Junho a Outubro). Analisando o evento de uma Friagem que atingiu a região de Manaus (Julho de 1969), Brinkman \& Ribeiro (1972) mostraram que a temperatura mínima naquele evento foi $12^{\circ} \mathrm{C}$ menor do que a média climatológica, provocando ventos intensos. No caso das variações dos elementos climáticos, Hamilton \& Tarifa (1978) analisaram a penetração de uma intensa frente fria (ocorrida em 1972), que provocou decréscimos na temperatura do ar em Cuiabá (MT) de até $13^{\circ} \mathrm{C}$. Outras observações importantes são a de que ocorre uma mudança de direção do vento (de Norte para Sul), a cobertura de nuvens é total e que o evento se extende até $700 \mathrm{hPa}$ (aproximadamente $3.000 \mathrm{~m}$ ), prolongandose por 3 dias (Fisch et al., 1997a). Ainda com relação às caracteristicas meteorológicas da superfície, Marengo et al. (1997) analisaram a extensão espacial das modificações causadas por duas Friagens moderadas ocorridas em 1994, observando que os efeitos mais pronunciados foram obtidos na região do sul de Rondônia (JiParaná), na qual a temperatura do ar atinge 
valores de $10^{\circ} \mathrm{C}$, aproximadamente $8^{\circ} \mathrm{C}$ abaixo da média climatológica, Nas regiões central e oeste da Amazônia (Manaus - AM e Marabá - PA, respectivamente), o decréscimo da temperatura do ar não foi tão grande, embora a quantidade de umidade atmosférica também tenha diminuído, pois ocorreu a invasão de ar polar (frio e seco). As modificações na estrutura vertical da atmosfera foram estudadas por Fisch et al. (1997a), que observou um aumento intenso da velocidade do vento (principalmente na componente meridional do vento), associado com um forte resfriamente (ao redor de $15^{\circ} \mathrm{C}$ na camada limite atmosférica). Estas informações foram coletadas em Julho de 1993, durante a realização do experimento de campo do RBLE.

\section{4 - Linhas de Instabilidade}

As Linhas de Instabilidade (LIs) que ocorrem na Amazônia são responsáveis pela formação de chuvas próximo à costa litorânea dos estados do Pará e Amapá, bem como de precipitação na Amazônia Central, durante a estação seca. Estudos preliminares (Coehn et al., 1989) mostraram que estas LIs são um dos sistemas atmosféricos atuantes na área leste do Pará e que contribuem com $45 \%$ da chuva que cai durante o período chuvoso. Estas linhas são caracterizadas por possuir grandes conglomerados de nuvens cumulonimbus e são formadas devido à circulação de brisa marítima, podendo-se prolongar para o interior do continente (denominadas LIP) ou não (LIC). Devido a suas dimensões, estas LIs são facilmente observadas por imagens de satélites. De acordo com Coehn et al. (1989), as LICs constituem $62 \%$ dos casos observados, sendo o restante $(38 \%)$ compreendido de LIPs. Cavalcanti (1982) realizou um estudo climatológico e observou que a formação destas linhas posiciona-se ao sul da Zona de Convergência InterTropical (ZCIT), sendo o período de maior frequência na época em que a ZCIT está mais organizada. Molion (1987) descreve a influência destas LIs na distribuição de chuva da Amazônia Central, observando que, durante à noite e devido à diminuição do contraste térmico oceano-continente, estas LIs praticamente se dissipam, para revigorarem-se no dia seguinte, com o aquecimento da superfície. Os aspectos climatológicos destas LIs na Amazônia foram estudadas observacionalmente por Coehn et al. (1989). Os resultados obtidos foram de que estas LIs podem atingir o extremo oeste da Amazônia, com velocidade de deslocamento entre 12 e $15 \mathrm{~m} \cdot \mathrm{s}^{-1}$ (aproximadamente 13 graus de longitude por dia). O comprimento e a largura médios destas LIs é de aproximadamente $1.500 \mathrm{~km}$ e $170 \mathrm{~km}$, respectivamente, sendo que os meses com maior frequência de ocorrência é entre Abril e Agosto (Coehn et al., 1989). Por outro lado, Coehn et al. (1995) estudaram a penetração de Linhas de Instabilidade na região Amazônia Central, durante o experimento ABLE-2B (Garstang et al, 1990) nos meses de Abril-Maio de 1987. Neste periodo as LIC compreenderam $23 \%$ dos casos, sendo o restante de LIPs. Em um estudo de caso de uma 
LIP intensa ocorrida no início de Maio, observou-se que foram dois mecanismos que provavelmente originaram e propagaram esta LIP: ventos de leste intensos em baixos niveis (entre $900 \mathrm{e}$ $650 \mathrm{hPa}$ ) e presença de uma fonte de calor a oeste da Amazônia. Os autores concluem que as LIs que se propagam na Amazônia são mecanismos complexos, em que ocorre interação entre escalas: larga, meso e microescala, sendo esta última provocada por circulações entre nuvens e o ambiente adjacente.

\section{5 - Brisa Fluvial}

A brisa fluvial é um mecanísmo físico no qual o ar, devido ao contraste térmico entre água-terra, move-se em direção do continente durante o dia e vice-versa à noite. Imagens de satélites mostram que as nuvens formam-se preferencialmente sobre o continente durante o dia, com movimentos de subsidência na área dos rios. Oliveira \& Fitzjarrald (1993) comprovam a existência desta circulação fluvial nos baixos níveis (até $1.500-2.000 \mathrm{~m}$ ), possuindo o sentido floresta/rio durante à noite e início da manhã, revertendo o sentido (rio/floresta) durante a tarde e início da noite. Observações radiométricas feitas por avião durante o experimento ABLE constataram um gradiente térmico enter rio/floresta de $-3^{\circ} \mathrm{C}$ durante o dia e $+6^{\circ} \mathrm{C}$ à noite (Oliveira \& Fitzjarrald, 1993). Certamente estas influências são mais intensas nas regiões em que a largura do rio é considerável, tais como próximo à Manaus (confluência os rios Negro e Solimões), Santarém (rios Tapajós e Amazonas) e Belém (rios Tocantins e parte sul da Foz do Rio Amazonas). Molion \& Dallarosa (1990) mostraram que, considerando-se 4 postos pluviométricos (1978-1988) próximos à Manaus, o menor indice anual $(1.843 \mathrm{~mm})$ foi o da estação instalada em uma ilha no rio Negro, sendo o maior indíce $(2.303 \mathrm{~mm}) \mathrm{na}$ localidade distante cerca de $100 \mathrm{~km}$.

\section{6 - Penetração de Sistemas Frontais e Organização da Conveç̧ão na Amazônia.}

Oliveira \& Nobre (1985) realizaram um estudo climatológico sobre a interação desta convecção tropical e a penetração de sistemas frontais na região SE do Brasil, utilizando de 5 anos (1977/1981) de imagens de satélites meteorológicos. Estes sistemas frontais provoca a organização e formação de uma banda de nuvens orientada no sentido NW/SE, e possue sua máxima intensidade nos meses de verão, aumentando o regime de precipitação da região (época chuvosa). Este aumento de convecção está relacionado com a intensificação do cavado em altos níveis, que é gerado pela penetração da frente.

\section{VARIAÇÕES CLIMÁTICAS DE LONGO-PRAZO NAAMAZÔNIA}

O desmatamento devido as atividades humanas na Amazônia aumentou rapidamente nas últimas décadas e há evidências de que esse dematamento afetou as características da baixa atmosfera. Resultados de simulações climáticas (Nobre et al., 1991; Manzi, 1993; Lean et al., 1996; 
entre outros) estimam uma diminuicão de 15 a $30 \%$ da precipitacão sobre Amazônia, caso a região seja toda desmatada. No entanto, até o presente momento, há poucas evidências observacionais de uma mudança climática na região.

Variações interanuais das chuvas na Amazônia têm sido uma constante preocupação para cientistas e vários estudos foram desenvolvidos considerando a resposta dos rios da Bacia Amazônica a essas variações. Importantes características do sistema climático da Amazônia podem ser extraídas de observações fluviopluviométricas, pois as variações da descarga fluvial do rio Solimões/ Amazonas e de seus afluentes estão sincronizadas com a distribuição da precipitacão na bacia e em suas subbacias. Marengo (1992) estudou as variações do nível do rio Negro como conseqüência da variação anual da precipitação relacionada a extremos do ENOS. Grandes desvios negativos nos níveis do rio Negro foram observados durante 1925-26, 1935-36, 1966-67 1979-80, 1983 e 1992, períodos que coincidem com a ocorrência de fortes eventos El-Niño (fase quente do ENOS), o que evidencia a influência do fenômeno sobre o nível desse rio. Para a Alta Amazônia (Peru e Equador), Gentry \& Lopez-Parodi (1980) apresentaram a hipótese, suportada por Rocha et al. (1989), de que um incremento das descargas dos rios durante as décadas entre 1960 e 1980 fosse devido a desmatamento. Essa hipótese, entretanto, não se aplica para a variabilidade interanual das cotas do rio Negro, uma vez que não há desmatamentos significativos ao longo da Bacia do rio Negro. Da mesma forma, análises de tendência para vazões de outros rios da Amazônia, como os rios Jamari (RO), Ji-Paraná (RO), Tocantins (TO e PA) não indicaram tendências climáticas. Em todos eles foi observado um aumento dos niveis durante os anos de 1970 e 1980, sendo porém que este aumento parece ser parte da variabilidade natural do clima e não um indicador de mudança climática.

É interessante ressaltar os resultados de Paiva \& Clarke (1995), que indicam uma tendência negativa de precipitação sobre boa parte do norte da Amazônia e da bacia do rio Xingu. Eles basearam seus resultados analizando séries de dados de precipitação de 48 postos pluviométricos, com intervalos de tempo entre 17 e 30 anos. Tardy et al. (1994) mostraram que, entre 1910 e 1990 , a chuva e vazões de água do rio Amazonas têm diminuido sistematicamente. Entretanto, estes resultados foram baseados em dados de precipitação em Manaus e nas vazões de água do rio Amazonas em Óbidos, sendo que essa úlltima série de dados não é necessariamente homogênea. $\mathrm{Na}$ parte sudoeste da Amazônia, Ferreira da Costa et al. (1997) compararam o total de chuva ocorrido em áreas de floresta e de pastagem durante o período compreendido entre 1992 e 1995 e obtiveram que o volume de água precipitado na floresta é cerca de $28 \%$ em média superior ao da pastagem, indicando uma tendência de diminuição, conforme obtidos por previsões 
climáticas ((Nobre et al., 1991; Manzi, 1993; Lean et al., 1996; entre outros).

Em recente relatório do Painel Intergovernamental de Mudanças Climáticas (IPCC, 1996), estudos sobre a variabilidade e mudanças climáticas indicam que é muito difícil separar a componente humana da componente climática, nas tendências observadas em dados de rios. A falta de dados de alta qualidade de precipitação e cotas/vazões em muitas partes de Amazônia tornam difícil o estudo da variabilidade e mudanças climáticas nesta região. Não só há muitas variáveis naturais, mas também a população muda o meio ambiente, o que na América Latina está acontecendo num ritmo muito acelerado. Até o presente momento, não foram observadas mudanças climáticas consistentes com os dados de rios analisados no Brasil e na América do Sul. Entretanto, um forte sinal do ENSO, isto é, de uma variabilidade interanual, é evidente no nordeste do Brasil e com certa limitaçâo na Amazônia do oeste.

\section{SIMULAÇÕES CLIMÁTICAS DO DESMATAMENTO DA FLORESTA TROPICAL}

Na última década, a Amazônia tem sido foco de atenção mundial devido à sua riqueza mineral, à sua grande biodiversidade de espécies florestais e também pelos efeitos que o desmatamento em grande escala pode provocar no clima regional e global.

Com relação à associação florestaclima, o desenvolvimento da informática facilitou a utilização de modelos numéricos de Circulação Geral da
Atmosfera (MCGAs) para se estudar $o$ efeito das trocas de energia entre a superfície e a atmosfera. Como ferramenta de análise da problemática do desmatamento, vários estudos de simulação numérica do clima em situações de floresta e desmatamento (troca de superfícies vegetadas de floresta por pastagens) já foram realizados (por exemplo Dickinson \& Henderson-Sellers, 1988; Lean \& Warrilow, 1989; Nobre et al., 1989; 1991; Henderson-Sellers et al., 1993; Lean \& Rowtree, 1993; Manzi, 1993; Lean et al., 1996). Na Figura 2 é apresentado, de forma compacta, os resultados do desmatamento na Amazônia obtidos por Nobre et al., (1991). De modo geral, os resultados obtidos convergem em que ocorrerá um aumento de temperatura do ar próximo à superfície (variando de 0,6 à $2,0^{\circ} \mathrm{C}$ ), uma redução nos totais de precipitação e evaporação (de 20 a $30 \%$ do valor de floresta) e uma estação seca mais prolongada. Estas modificações certamente acarretarão implicações ecológicias gravíssimas. Em um estudo preliminar, Nobre et al, (1989) estudaram os impactos climáticos devido ao desmatamento $\mathrm{e}$ obtiveram um aumento da temperatura do ar de $1,3^{\circ} \mathrm{C}$. Este aquecimento relativo da superficie de terra desmatada e do ar imediatamente acima é consistente com reduções na evapotranspiração e no fluxo de calor latente, uma vez que uma maior fração de energia radiativa está disponível para aquecer a superfície terrestre e $o$ ar acima. Além disso, a redução no comprimento de rugosidade diminui a eficiência dos 

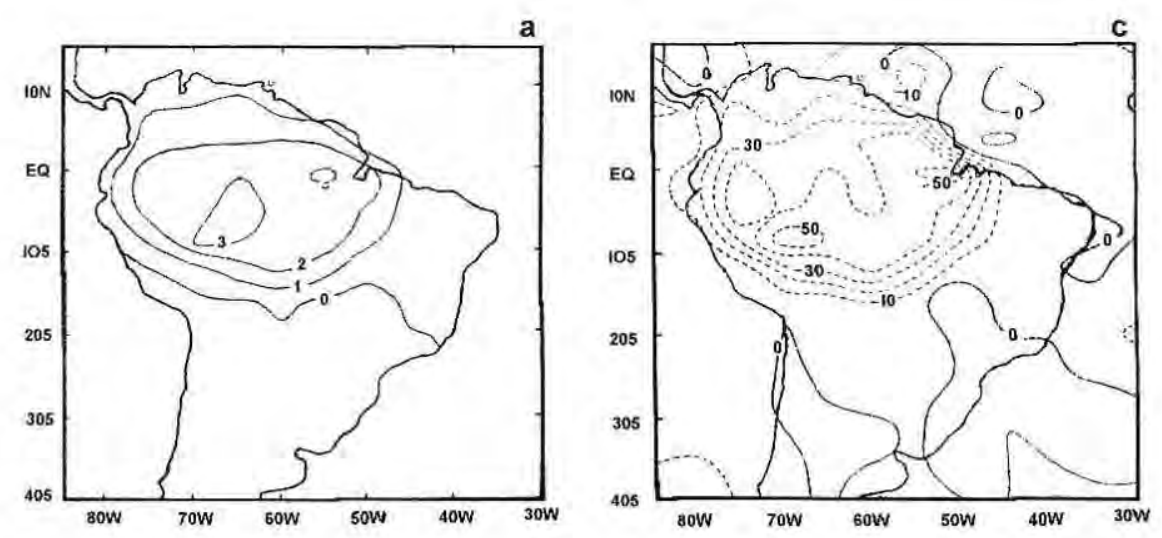

b
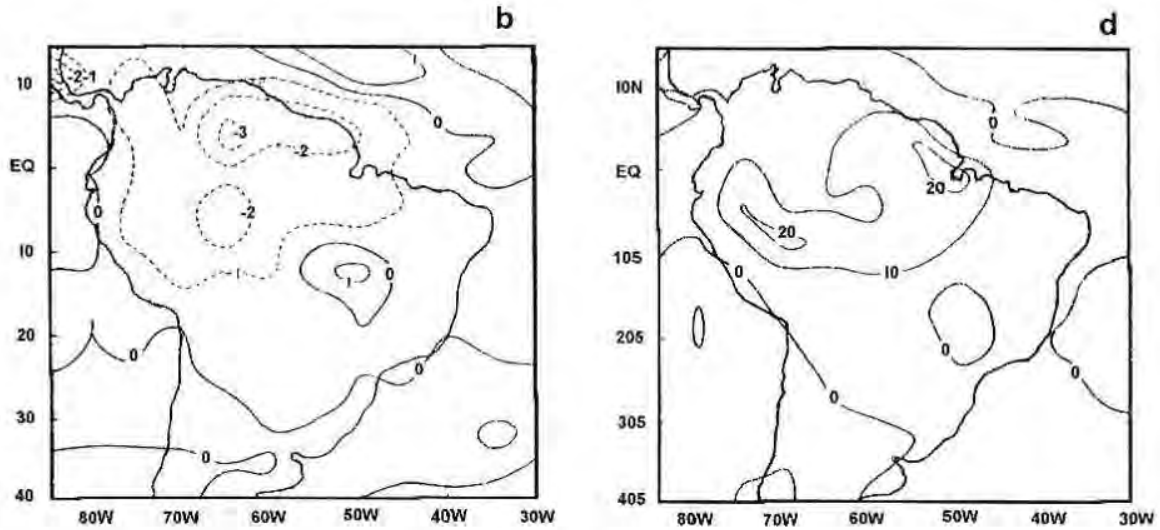

Figura 2. Modificações microclimáticas decorrentes do desmatamento da Amazônia: a) temperatura do ar (graus), b) temperatura do solo (graus), c) precipitação (mm) e d) evaporação anual $(\mathrm{mm})$. (Extraído de NOBRE et al., 1989).

processos de troca turbulenta, contribuindo para um aumento de calor na superfície e na camada próxima à ela. No caso do balanço de energia à superfície (média espacial da área considerada) mostra que a radiação solar absorvida pela superficie é menor no caso desmatado $\left(186 \mathrm{~W}, \mathrm{~m}^{-2}\right)$ do que na área de floresta (204 W. $\left.\mathrm{m}^{-2}\right)$, devido às variações do albedo: este aumentou de $12,5 \%$ no caso floresta para $21,6 \%$ no cenário pastagem. O estudo efetuado por Lean et al. (1996) representa as condições de fronteira e inicial mais realistas do cenário da Amazônia, uma vez que os parâmetros de controle (por exemplo fração da vegetação coberta, tipo de solo, difusividade hidraúlica etc) e de superfície (albedo, comprimento de rugosidade, índice de área foliar etc) foram extraidos do conjunto de dados do ABRACOS. Os resultados obtidos foram coincidentes com os descritos por Nobre et al. (1989) com redução na evaporação e precipitação e aumento da temperatura do ar na superficie. A diferença mais notável foi que a redução 
na evaporação de $0,8 \mathrm{~mm}$. dia ${ }^{-1}$ (do cenário de floresta $\left(4,3 \mathrm{~mm} \cdot\right.$ dia $\left.^{-1}\right)$ para pastagem $\left(3,5 \mathrm{~mm} \mathrm{dia}^{-1}\right)$ foi parcialmente compensada por um aumento de convergência de umidade, resultando em uma redução de precipitação menor (redução de $7 \%$ do caso floresta para pastagem). Também ocorrem diferenças regionais (Amazônia Sul e Norte): no caso da precipitação, por exemplo, ocorre uma redução em todos os meses da parte sul, embora existam meses com redução e outros meses com aumento na parte norte. Para a temperatura do ar, o valor global na pastagem foi a de um aumento de $2,3^{\circ} \mathrm{C}$, devido à um crescimento do fluxo de calor sensivel $(+30 \%$ do caso de floresta). O objetivo deste texto é o de apresentar, de forma sucinta, resultados obtidos por simulações climáticas numéricas. Maiores detalhes sobre as equações da dinâmica do fluído utilizadas, métodos de discretização, hipóteses simplificadoras etc, podem ser encontradas nas próprias referências mencionadas acima.

Os dois artigos supra citados (Nobre et al., 1989; Lean et al., 1996) abordaram as modificações climáticas a nivel regional. Por outro lado, Fisch et al. (1997b) analisaram com detalhes o comportamento de variáveis meteorológicas na região específica de Ji-Paraná (RO) em áreas de floresta e pastagem, utilizandose de resultados gerados por Lean at al. (1996). Nestas análises usou-se um conjunto de dados (valores horários durante um período de 15 meses) gerados após 5 anos de integração. De modo geral, a substituição de floresta por pastagem provoca, a nível sazonal, uma redução no saldo de radiação de ondas curtas $(8 \%)$ e total $(3 \%)$, um aumento na temperatura média do ar $\left(0,9^{\circ} \mathrm{C}\right)$, um redução pequena na umidade específica do ar, um aumento da velocidade do vento, uma redução na evaporação e precipitação (de $20 \%$ e $14 \%$, respectivamente) e um periodo de seca mais prolongado (a época seca (total mensal inferior a $50 \mathrm{~mm}$ ) estende-se de Junho-Julho no cenário floresta para Maio à Agosto no caso pastagem). Com a escolha de um mês tipicamente úmido (Janeiro) e um mês ao final da época seca (Setembro), analisou-se o comportamento horário dos fluxos de energia e dos elementos climáticos. O saldo de radiação (ondas curtas e total) é superior na floresta em relação à pastagem, em ambas as estações. A razão de Bowen é tipicamente de $+0,3$ durante a época chuvosa, aumentando para valores entre 1,0 e 3,0 durante a estação seca. No caso da temperatura do ar, a floresta apresenta um valor máximo maior do que de pastagem (diferença de temperatura de $1,2^{\circ} \mathrm{C}$ ) durante o período das chuvas e é inferior ao minimo da temperatura da pastagem na estação seca (diferença de temperatura de $-2,5^{\circ} \mathrm{C}$ ). Obteve-se valores de umidade específica similares na floresta e pastagem durante a estação chuvosa (tipicamente 16 g. $\mathrm{kg}^{-1}$ ), embora diferentes (floresta mostra valores em tomo de $16 \mathrm{~g} . \mathrm{kg}^{-1}$ e a pastagem possui valores de $10 \mathrm{~g} . \mathrm{kg}^{-1}$ ) na época seca. A velocidade do vento é mais intensa na pastagem em relação à floresta, sendo que no período seco a pastagem apresenta ventos de até $3,5 \mathrm{~m} \cdot \mathrm{s}^{-1}$. Rocha et al. (1996) também utilizaram de simulação climática para estudar o efeito do desmatamento local no clima da Amazônia, encontrando 
que a evapotranspiração e precipitação na área de floresta é praticamente insensivel para variações de umidade no solo, ao passo que a pastagem possui suas caracteristicas fortemente associadas à umidade. Os autores encontraram que uma saturação inferior à $60 \%$ conduz à baixas taxas de evaporação e de precipitação. Estes valores foram posteriormente confirmados observacionalmente por Wright et al. (1992).

Buscando comprovar as variações meteorológicas decorrentes do desmatamento, Paiva \& Clarke (1995) analisaram estatisticamente as séries temporais de 48 postos pluviơmétricos na Amazônia e encontraram que, embora haja tendências estatísticas sobre as anomalias positivas ou negativas, há indícios de que tendências negativas são mais comuns de ocorrerem do que as positivas, sendo também mais frequente nas partes da Amazônia Central e Oeste. A parte leste possue mais tendências positivas, provavelmente em função da proximade do Oceano Atlântico e brisa maritima. Outros estudos que demonstram a variabilidade da precipitação são os de Rocha et al. (1989) e Chu \& Hastenrath (1994).

\section{MICROMETEOROLOGIA DE FLORESTA}

A seguir, descrever-se-á os principais resultados de micrometeorologia de floresta e pastagem, obtidos pelo Projeto ABRACOS (Nobre et al., 1996; Gash \& Nobre, 1997). Estes resultados foram baseados em observações e dados coletados nos três pontos experimentais do Projeto ABRACOS. Ressalta-se que trabalhos cientificos anteriores foram realizados (por exemplo, Shuttleworth,
1988; Sa et al., 1988; Viswanadham et al., 1990) principalmente com os dados da torre micrometeorológica da Reserva Ducke (Manaus, AM).

"Nos quatros anos de medidas de campo do Projeto ABRACOS ocorreram sete campanhas intensivas de monitoramento do clima. O objetivo dessas campanhas de campo foi o de avaliar os parâmetros físicos que descrevem a micrometeorologia dos sítios experimentais e fornecer estimativas de todas as componentes do balanço de energia, incluindo evaporação, a qual pode ser utilizada para calibrar modelos da superfície vegetada. Em média os sitios experimentais de floresta absorveram $11 \%$ mais radiação do que as pastagens. Isto advém do fato da floresta refletir menos radiação solar e emitir menos radiação de ondas longas. $\mathrm{O}$ albedo médio da floresta foi de 0,13 , ligeiramente mais alto do que o valor usualmente utilizado em simulações numéricas de desmatamento, enquanto que $o$ albedo médio da pastagem foi de 0,18 , ligeiramente menor que os valores habitualmente utilizados. Surpreendentemente as gramíneas das pastagens não apresentaram uma forte sazonalidade do albedo, ao passo que o albedo da floresta mostrou uma variação sazonal bem definida, que não ocorre devido aos efeitos de variaçôes do angulo de elevação solar ou as variações de nebulosidade, mas está correlacionado com a umidade do solo. Embora o albedo dos sítios de pastagem não tenha mostrado uma clara tendência sazonal, variações de mês a mês foram observadas, estando associadas ao indice de área foliar. Em Ji-Paraná, 
diferenças sistemáticas na radiação solar incidente entre os sitios experimentais de floresta e pastagem foram observadas durante a estação seca. Estas diferenças podem estar relacionadas com o aumento de nebulosidade sobre a pastagem durante aquela época do ano, fato este evidenciado por Cutrim et al. (1995). Em se confirmando essas observações, é um resultado importante na medida que indica um efeito direto da mudança de cobertura vegetal em um fenômeno atmosférico de mesoescala.

As pastagens apresentaram temperaturas máximas durante o dia mais altas e amplitudes de temperatura também mais altas. Geralmente o mínimo de temperatura foi menor à noite para a pastagem. Este resultado está associado provavelmente as baixas velocidades do vento próximo à superficie para as pastagens à noite, $o$ que pode levar à redução dos processos turbulentos de mistura na vertical e maior estabilidade atmosférica. A temperatura durante $o$ dia na área urbana de Manaus foi sistematicamente mais alta que aquela nas duas áreas rurais (pastagem e floresta), mas as temperaturas na cidade à noite foram similares àquelas sobre a floresta. Há pequena variação sazonal de temperatura em Manaus ou Marabá, porém há um resfriamento considerável durante a estação seca em Ji-Paraná, associada à advecção de ar frio de latitudes extratropicais no Hemisfério Sul, devido à passagem de sistemas frontais. Um marcante ciclo anual de umidade foi observado em Ji-Paraná e Marabá, mas não foi observado em Manaus. Valores mais baixos de umidade durante a estação seca estão associados à subsidência de grande escala, que é predominante próximo às fronteiras do domínio florestal (como nas regiões de Marabá e Ji-Paraná no sudeste e sudoeste da Amazônia, respectivamente). A umidade do solo estudada continuamente durante todo o projeto ABRACOS mostrou que, durante a estação seca, houve sistematicamente maior extração de água no solo sob a floresta, resultando em perfis mais secos ao final da época seca. Há claras indicações de que a floresta está extraindo água a profundidade maiores que $3,6 \mathrm{~m}$ (profundidade máxima das medidas de umidade do solo). Estas indicações encontram suporte nas medidas de variações máximas de armazenamento registradas para cada um dos sítios experimentais, $\mathrm{O}$ termo de armazenamento do balanço de água não foi nulo ao final do ciclo anual e, se esses resultados fossem extrapolados para a escala regional, a diferença entre a precipitação e vazão fluvial não resultariam na evaporação média anual de grande escala. O quadro geral de água no solo mostra que existem grandes diferenças nas variações sazonais de conteúdo de água no solo, tanto entre floresta e pastagem como entre os sitios experimentais. Essas diferenças ocorrem como resultado dos diferentes regimes de precipitação, combinados com as diferenças propriedades do solo, comportamento do lençol freático e profundidade das raizes das florestas e gramíneas.

Durante a estação chuvosa, a partição de energia para evaporação foi similar para floresta e pastagem, 
mas a evaporação total da pastagem nesta estação foi tipicamente 10 a 15\% menor em comparação com a floresta devido a reduzida energia disponivel na pastagem e as rugosidades aerodinâmicas mais suavizadas. Durante a estação seca, as pastagens, que têm raizes mais rasas, foram todas afetadas pela diminuição das reservas de água no solo, ainda que com intensidades variadas dependendo do tipo de solo e precipitação. Nos solos argilosos de Manaus, a transpiração das pastagens declinou rapidamente depois de somente 10 dias sem chuvas. Em contraste, nenhuma atenuação significativa em transpiração foi observada em qualquer dos sitios de floresta durante os períodos secos, inclusive durante as estações secas mais longas em Marabá e Ji-Paraná.

Medições dos fluxos turbulentos de $\mathrm{CO}_{2}$ sobre a floresta da Reserva Jaru mostraram que ocorreu um acúmulo de carbono pela vegetação, que é o resultado do balanço entre a quantidade de carbono absorvida durante a fotossintese e liberada pela respiração. Se for extrapolado para toda a região, estas estimativas significam que a Amazônia seria um sorvedouro de aproximadamente 0,5 Gigatoneladas de carbono por ano e teria um papel importante no efeito estufa, se todo este carbono fosse liberado instantaneamente para a atmosfera.

A camada limite atmosférica durante condições convectivas atingiu altura de 700 a $1.000 \mathrm{~m}$ mais altas sobre áreas com desmatamento do que sobre áreas de florestas na região de Ji-Paraná, o que mostrou-se consistente com as observações de aumento do fluxo de calor sensivel à superficie e diminuição da evaporação sobre pastagens em comparação com a floresta. Observou-se também uma pequena diminuição da quantidade total de vapor d'água sobre a pastagem em relação a floresta. A arquitetura de faixas de floresta inseridas em grandes extensões de áreas de pastagem é tal que a justaposição deste dois tipos de superficie (floresta fria e úmida e pastagem quente e seca) pode provocar movimentos de mesoescala (circulação térmica), auxiliando a erosão da camada limite noturna na pastagem. Também ocorre aumento de turbulência e advecção de energia nesta situação."

\section{EXPERIMENTOS METEOROLÓGICOS REALIZADOS NA REGIÃO AMAZÔNICA}

Nas últimas duas décadas, vários experimentos micrometeorológicos integrados (veja resumo na Tab. 1) foram realizados na região amazônica, com o objetivo de aumentar os conhecímentos relativos à interação entre floresta tropical e a atmosfera. Individualmente, vários estudos foram feitos por pesquisadores do INPA, Museu Emílio Gueldi e Universidade Federal do Pará (entre outros), sobre estas interações. $\mathrm{O}$ experimento ARME (Amazonian Research Micrometeorological Experiment) teve como objetivo a coleta de dados micrometeorológicos da partição de energia pela floresta amazônica e estimativas de evapotranspiraçâo. Vários resultados científicos foram encontrados, dentro dos quais ressalta-se o fato de que a floresta tropical não sofre $o$ 
Tabela 1. Descrição resumida dos experimentos micrometeorológicos na Amazônia

\begin{tabular}{|c|c|c|c|c|c|c|}
\hline Nome & Local & Período & dados coletados & situaçãoatual & Referência & EntidadesEnvolvidas \\
\hline ARME & Manaus (AM) & $1983-1986$ & $a, b, t, g$ & disponivel & Shuttleworth (1987) & $1,2,4,6,8,10$ \\
\hline ABLE & Manaus (AM) & $1985(2 \mathrm{~A})$ e $1987(2 \mathrm{~B})$ & $a, b, c, d, e$ & disponivel & ABLE $(1988,1990)$ & $1,2,3,4,6,8,12,13$ \\
\hline FLUAMAZON & Amazônia & 1989 & $a, d$ & disponível & ROCHA (1991) & $2,4,6,9$ \\
\hline \multirow[t]{3}{*}{ ABRACOS } & Manaus (AM) & $1990-94$ & $a, b, f, g$ & disponível & Nobre et al. (1996) & $1,2,4,6,7,8,9,10,11$ \\
\hline & Marabá $(P A)$ e & & & & & \\
\hline & Ji-Paraná (RO) & & & & & \\
\hline RBLE & Ji-Paraná (RO) & $1992-94$ & $a, b, c, d, f$ & disponivel & Fisch (1996) & $2,3,4,5,6,10$ \\
\hline MACOE & Manaus (AM) & 1995 & $a, b, c, f$ & consistência & Culf et al. (1997) & $1,2,4,5,6,7,10,11$ \\
\hline
\end{tabular}

(1) Instituto Nacional de Pesquisas da Amazônia (INPA);

(2) Instituto Nacional de Pesquisas Espaciais (INPE);

(3) Universidade de São Paulo (USP);

(4) Universidade Federal do Pará (UFPA);

(5) Universidade Federal de Alagoas (UFAL);

(6) Centro Técnico Aeroespacial (CTA);

(7) Universidade de Brasilia (UnB)

(a) estaçâo meteorológica de superfície

(b) fluxos turbulentos de momentum, de calor sensível e latente

(c) balăo cativo

(d) radiossondagem

(e) aviões instrumentados

(f) medidas de umidade no solo

(g) medidas de fisiologia vegetal
(8) Empresa Brasileira de Pesquisa Agropecuária (EMBRAPA);

(9) Centro de Energia Nuclear na Agronomia (CENA)

(10) Institute of Hydrology - Reino Unido $(\mathrm{IH})$

(11) University of Edinburgh - Reino Unido (UoE)

(12) National Aeronautics and Space Admistration - Estados Unidos - (NASA):

(13) University of New York at Albany - Estados Unidos (SUNYA); 
efeito da deficiência hídrica provocada pela falta de chuvas, evapotranspirando na taxa potencial ao longo do ano (Shuttleworth, 1988). Posteriormente, o experimento ABLE (Amazonian Boundary Layer Experiment) foi realizado com o intuito de coletar dados da estrutura da atmosfera da região amazônica para estudar liberação e ciclos de gases e aerossóis. Os principais resultados científicos estão compilados em dois números especiais (ABLE-2A, 1988; ABLE2B, 1990) e em Garstang et al. (1990). $\mathrm{O}$ balanço hídrico em larga-escala durante este experimento foi analisado por Souza (1991). Este mesmo assunto foi objeto de um outro experimento científico realizado em Novembro e Dezembro de 1989 e denominado FLUAMAZON (Fluxo de Umidade na região Amazônica). O objetivo deste experimento foi o de coletar dados de ar superior (radiossondagem) para realizar balanço de umidade na Amazônia, juntamente com medidas isotópicas do vapor d'água e seus resultados foram analisados por Rocha (1991). Com o intuito de coletar dados dos fluxos de energia e dos elementos climáticos sobre as superficies de floresta tropical e de pastagem em três localidades distintas da Amazônia, iniciou-se o projeto ABRACOS (Anglo Brazilian Amazonian Climate Observational Study), que teve a realização de missões de coleta de dados em épocas sêcas e úmidas, durante os anos de 1991-1995. Vários resultados científicos importantes foram alcançados (veja um resumo em Nobre et al. (1996), dentre os quais destacam-se a sazonalidade do albedo de floresta tropical (Culf et al., 1995), a sazonalidade da evapotranpiração na área de pastagem, mas não na floresta (Wright et al., 1992) etc. Os conhecimentos científicos sobre a influência do desmatamento no clima na estrutura da camada limite atmosférica foram aumentados com a realização do experimento RBLE (Rondônia Boundary Layer Experiment), com 3 campanhas de coleta de dados durante época seca, em regiões de floresta e pastagem em Ji-Paraná (RO). As campanhas de coleta de dados foram realizadas em simultâneo com medidas do Projeto ABRACOS. Os principais resultados estão compilados em Fisch (1996) e mostram que a camada limite convectiva sobre a área de pastagem é muito mais desenvolvida do que sobre floresta, sendo esta diferença (em torno de 1.000 metros mais profunda) devido à maneira como é feito a partição de energia na pastagem: o fluxo de calor sensível é praticamente igual ao de calor latente. Por outro lado, durante as condições noturnas, a camada limite noturna é mais profunda na floresta $(350 \mathrm{~m}$ de altura) do que na pastagem $(230 \mathrm{~m})$, pois a rugosidade e a consequente turbulência mecânica (ventos) auxilia o transporte de energia na floresta. A descontinuidade térmica na pastagem é superior a da floresta. Lyra et al. (1994) mostram que a estrutura da camada limite atmosférica (CLA) sobre a região de floresta em Ji-Paraná apresenta-se compativel com as observações realizadas na floresta tropical do Congo, ressaltando que a CLA sobre a área de pastagem é, em média, $66 \%$ superior a da floresta, 
alèm de não entrar em colapso ao final da tarde/inicio da noite, mantendo um aspecto estacionário durante todo $o$ periodo noturno. O papel da vegetação de floresta tropical na liberação/ absorção de $\mathrm{CO}_{2}$ atmosférico está sendo estudado, com a realização de uma campanha de coleta de dados do MACOE (Manaus Atmospheric $\mathrm{CO}_{2}$ Experiment), realizado em novembro de 1995, na região de Manaus (AM). O objetivo deste experimento foi o de coletar dados do perfil de $\mathrm{CO}_{2}$ na camada limite noturna em regiões de floresta tropical, Os principais resultados (Culf et al., 1997) obtidos foram que a concentração dentro do dossel da floresta é fortemente influenciada pela formação de inversões térmicas próximo à superfície e que existe grande variabilidade espacial dos fluxos de $\mathrm{CO}_{2}$ liberados pela floresta. Esta última conclusão foi baseada na realização de balanço de $\mathrm{CO}_{2}$ na camada limite atmosférica. Finalmente, em um futuro bastante próximo, será realizado um grande experimento internacional (LBA - Large Scale Biosphere-Atmosphere Experiment in Amazonia) na região amazônica, que visa integrar todos estes resultados já obtidos, além de tentar entender como a Amazônia funciona atualmente como uma entidade regional. Outros objetivos são o de conhecer como as mudanças nos usos da terra e no clima irão afetar o funcionamento biológico, químico e fisico da Amazônia, incluindo a sustentabilidade do desenvolvimento na região e sua a influência no clima. O experimento LBA será uma colaboração internacional, envolvendo
Brasil, Estados Unidos e Europa (Reino Unido, Holanda, Alemanha, França, entre outros). O periodo de coleta de dados está planejado para ocorrer entre 1999-2000, com as análises estendendo-se até o ano 2003.

\section{AGRADECIMENTOS}

Os autores desejam expressar seus agradecimentos à todos aqueles que, direta ou indiretamente, realizam pesquisas na Amazônia, tentando compreender melhor a influência da floresta na determinação e caracterização do clima da região, em busca de melhores condições de vida dos amazônidas.

\section{Bibliografia citada}

ABLE-2A 1988. Número Especial contendo artigos cientificos do Experimento ABLE2A. Journal of Geophysical Research, 93(D2):1349-1624.

ABLE-2B 1990. Número Especial contendo artigos cientificos do Experimento Able2B. Journal of Geophysical Research, 95(DIO):16721-17050.

Absy, M.L. 1985. Palinology of Amazonia: the history of the forests as revealed by the palynological record. In: G.T. Prance; T.E. Lovejoy (eds). Amazônia. Pergamon Press, Oxford, Reino Unido, p.42-72.

Aceituno, P. 1988. On the functioning of the southern oscillation in the South America sector - Part I: surface climate. Monthly Weather Review, 116(3):505-524.

Brinkman, W.L.F,; Ribeiro, M.N.G. 1972. Air temperatures in Central Amazônia. III Vertical temperature distribution on a clearcut area and in a secondary forest near Manaus (cold front conditions July 10th 1969). . Acta Amazonica, 2(3):25-29.

Carvalho, A.M.G. 1989. Conexões entre $a$ circulação em altitude e a conveç̧ão 
sobre a América do Sul. Dissertação de Mestrado, Instituto Nacional de Pesquisas Espaciais, São José dos Campos, São Paulo, $121 \mathrm{p}$.

Cavalcanti, I.F.A. 1982. Um estudo sobre interações entre sistemas de circulação de escala sinótica e circulações locais. Dissertação de Mestrado, Instituto Nacional de Pesquisas Espaciais, São José dos Campos, São Paulo, 113 p.

Chu, P.S.; Yu, Z.P.; Hastenrath, S. 1994. Detecting climate change concurrent with deforestation in the Amazon Basin: which way has it gone? Bulletin of American Meteorological Society, 75(4):579-583.

Coehn, J.C.P.; Silva Dias, M.A.F.; Nobre, C.A. 1989. Aspectos climatológicos das linhas de instabilidade na Amazônia. Climanálise Boletim de Monitoramento e Análise Climática, 4(11):34-40.

1995. Environmental conditions associated with Amazonian Squall Lines: a case study. Monthly Weather Review, 123(11):3163-3174.

Culf, A.D.; Fisch, G.; Hodnett, M.G. 1995, the albedo of Amazonia forest and ranchland. Journal of Climate, 8(6): 1544-1554.

Culf, A.D.; Fisch, G.; Malhi, Y.; Costa, R.F.; Nobre, A.; Marques Filho, A. de O.; Gash, J.H.C.; Grace, J. 1997. Carbon dioxide measurements in the nocturnal boundary layer over Amazonia Forest. Hydrology and Earth Science System - TIGER Special Issue (aceito para publicação).

Cutrim, E; Martin, D.W; Rabin, R. 1995. Enhancements of cumulus cloud cover over deforested lands in Amazonia. Bulletin of American Meteorological Society, 76(10): 801-1805.

Dickinson, R.E.; Henderson-Sellers, A. 1988. Modelling tropical deforestation: a study of GCM land-surface parametrizations. Quarterly Journal of Royal Meteorological Society, 1I4(480):439-462.

Feitosa, J.R.P.; Ferreira da Costa, R.; Fisch, G.; Sousa, S.S.; Nobre, C.A . 1997. revista Brasileira de Agrometeorologia (submetido).

Ferreira da Costa, R.; Feitosa, J.R.P.; Flisch, G.; Souza, S.S.; Nobre, C.A. 1997. Variabilidade diurna da precipitação em regiōes de floresta e de pastagem na Amazônia. Acta Amazônica (submetido).

Figueroa, S.N.; Nobre, C.A. 1990. Precipitions distribution over Central and Western Tropical South America. Climanálise Boletim de Monitoramento e Análise Climática, 5(6):36-45.

Fisch, G. 1990. Climatic Aspects of the Amazonian Tropical Forest. Acta Amazonica, 20 (único):39-48.

.... 1996. Camada Limite Amazônica: aspectos observacionais e de modelagem. Tese de Doutorado, Instituto Nacional de Pesquisas Espaciais, São José dos Campos, São Paulo, 171 p.

Fisch, G.; Culf, D.A.; Nobre, C.A. 1997a. A note of the modification of ABL structure due to a FRIAGEM in the Amazon region (submetido à Boundary Layer Meteorology).

Fisch, G.; Lean, J.; Wright, I.R.; Nobre, C.A. 1997b. Simulaçôes climáticas do efeito do desmatamento na região Amazônica: estudo de um caso em Rondônia. Revista Brasileira de Meteorologia, 12(1):33-48,

Garstang, M.; Ulanski, S.; Greco, S.; Scala, J.; Swap, R.; Fitzjarrald, D.; Browell, E.; Shipman, M.; Connors, V; Harris, R.; Talbot, R. 1990. The amazon boundary layer experiment - a meteorological perspective. Bulletin of American Meteorological Society, 71(1):19-32.

Gash, J.H.C.; Nobre, C.A. (1997). Climatic effects of Amazonian deforestation: some results from ABRACOS. Bulletin of American Meteorological Society, 78(5):823-830.

Gentry, A.; Lopez-Parodi, J. (1980). Deforestation and increased flooding in the upper Amazon. Science, 210: 1354-1356.

Hamilton, M.G. ;Tarifa, J.R, 1978. Synoptic aspects of a polar outbreak leading to frost in tropical Brazil, July 1972. Monthly Weather Review, 106(11):1545-1556.

Henderson- Sellers, A.; Dickinson. R.E.; Durbidge, T.B.; Kennedy, P.J.; McGuffie, K.; Pitman, A.J، 1993. Tropical deforestation modelling local to regional scale climate change. Journal of Geophysical 
Research, 98(D4):7289-7315.

Horel, J.D.; Hahmann, A.N.; Geisler, J.E. 1989. An investigation of the annual cycle of convective activity over the tropical Americas. Journal of Climate, 2(11):1388-1403.

Instituto Nacional de Pesquisas Espaciais (INPE). 1992. Deforestation in Brazilian Amazonian. São José dos Campos, $4 \mathrm{p}$.

IPCC, 1996. Observed climate variability and change. In: J.T. Houghton, L.G. Meira Filho, A. Kattember; K. Maskell (eds). Climatic change 1995- the IPCC scientific assemsment. Cambrigde University Press, Cambrigde, Reino Unido, p. 137-181.

Jones, C.; Horel, J.D. 1990. A note on the upper level divergence field over South America during the summer season. Revista Brasileira de Meteorologia, 5(2):411-416.

Kayano, M.T;; Moura, A.D. 1986. O El-Niño de 1982-83 c a precipitação sobre a América do Sul. Revista Brasileira de Geofisica, 4(1-2):201-214.

Kousky, V.E.; Kagano, M.T. 1981. A climatological study of the tropospheric circulation over the Amazon region. Acta Amazonica, 11(4):743-758.

Lean, J.; Button, C.B.; Nobre, C.A.; Rowntree, P.R. 1996. The simulated impact of Amazonian deforestation on climate using measured ABRACOS vegetation characteristics. In: Gash, J.H.C.; Nobre, C.A.; Roberts, J.M.; Victoria, R.L. (eds). Amazonian deforestation and climate. John Wiley \& Sons, Chichester, Reino Unido, p. 549-576.

Lean, J.; Rowntree, P.R. 1993. A GCM simulation of the impact of Amazonian deforestation on climate using an improved canopy representation. Quarterly Journal of Royal Meteorological Society, 119(511):509-530.

Lean, J; Warrilow, D.A. 1989. Simulation of the regional climatic impact of Amazon deforestation. Nature, 342:411-413

Lyra, R.; Nobre, C.; Fisch, G.; Rocha, E.; Rocha, H.; Souza, S. 1994. Efeitos do desmatamento sobre a termodinâmica da baixa atmosfera. Anais do VIII Congresso
Brasileiro de Meteorologia, Sociedade Brasileira de Meteorologia, Belo Horizonte, p. 81-84.

Maia Alves, S.F. 1997. Análise comparativa do regime de precipitação e de evapotranspiração em áreas desmatadas e florestadas na regiâo amazónica. Trabalho de Graduação, Instituto Tecnológico da Aeronáutica, Centro Técnico Aeroespacial, São José dos Campos, São Paulo, 72 p.

Manzi, A. O. 1993. Introduction d'un schéma des transferts sol-vegetation-atmosphére dans un modéle de circulation générale el application a la simulation de la deforestation Amazonienne. Tese de Doutorado, Universidade Paul Sabatier, Toulouse, França, $230 \mathrm{p}$.

Marengo, J. 1991. Extreme climatic events in the Amazon Basin and their associations with the circulation of the global tropics. Tese de Doutorado, Department of Meteorology, University of Wisconsin, Madison, Wisconsin, USA, 147 pp.

... 1992. Interannual variability of surface climate in the Amazon basin. International Journal of Climatology, 12(8):853-863.

1995. Interannual variability of deep convection in the tropical South American sector as deduced from ISCCP C2 data. International Journal of Climatology, 15(9):995-1010.

Marengo, J.; Druyan, L.; Hastenrath, S. 1993. Observational and modelling studies of Amazonia interannual climate variability. Climatic Change, 23(3):267-286.

Marengo, J.; Hastenrath, S. 1993. Case studies of extreme climatic events in the Amazon basin. Journal of Climate, 6(4):617-627.

Marengo, J. Nobre, C.A., Culf, A.D. 1997. Climatic impacts of the "Eriagens" in forested and deforested areas of the Amazon Basin. Jounal of Climate, 36(11):1553-1566.

Marques, J.; Salati, E; Santos, J.M. 1980. Cálculo da evapotranpiração real na Bacia Amazônica através do método aerológico. Acta Amazonica, 10(2):357-361.

Marques Filho, A. de O.; Góes Ribeiro, M.N.; Fattori, A.P.; Fisch, G.; Januário, M. 1986. Evaporação Potencial de Florestas, Acta 
Amazonica, 16/17(único):277-292.

Matsuyama, H. 1992. The water budget in the Amazon River Basin during the FGGE Period. Journal of Meteorological Society of Japan, 70(6): 1071-1083.

Molion, L.C.B. 1975. Climatonomic study of the energy and moisture fluxes of Amazon Basin with consideration of deforestation offects. Tese de Doutorado, Department of Meteorology, University of Winconsin, Madison, Wisconsin, USA, $140 \mathrm{p}$.

1987. Climatologia Dinãmica da região Amazônica: mecanismos de precipitação. Revista Brasileira de Meteorologia, 2(1):107-117.

.... 1993. Amazonia räinfall and its variability. In: Bonell, M.; Hufschmidt, M.M.; Gladwell, J.S, feds). Hydrology and water manegement in the humid tropics. International Hydrology Series, Cambrigde University Press, Cambrigde, Reino Unido, p. 99 - 111.

Molion, L.C.B.; Carvalho, J.C. 1987. Southern Oscillation and river discharge of selected rivers of tropical south america. In: Anon (ed.). Conference of Geophysical Fluid Dynamics with special emphasis on "El Niño. Ministério da Ciência e Tecnologia e Centro Latinoamericano de Física. São José dos Campos, p. 343 - 354.

Molion, L.C.B.; Dallarosa, R.L.G. 1990. Pluviometria da Amazonia: são os dados confiáveis? Climanálise - Boletim de Monitoramento e Análise Climática, $5(3): 40-42$.

Nobre, C.A.; Gash, J.H.C.; Roberts, J.M.; Victoria, R.L. 1996. Conclusōes do projeto ABRACOS. In: Gash, J.H.C.; Nobre, C.A.; Roberts, J.M.; Victoria, R.L. (eds). Amazonian deforestation and climate. John Wiley \& Sons, Chichester, Reino Unido, p. 586-595.

Nobre, C.A.; Oliveira, A. 1987. Precipitation and circulation anomalies in south america and the 1982-83 El Niño/Southern Oscillation episode. In: Anon (ed.). Conference of Geophysical F/uid Dynamics with special emphasis on "El Niño. Ministerio da Ciência e Tecnologia e Centro Latinoamericano de Física. São José dos Campos, p. 325-328;

Nobre, C.A.; Rennó, N.O. 1985. Droughts and floods in south America due to the 19821983 El Nino/Southern Oscillation episode. Relatório Técnico INPE 3408 PRE/677, 4p.

Nobre, C.A.; Sellers, P.J.; Shukla, J. 1991. Amazonian Deforestation and regional climate change. Journal of Climate, 4(10):957-988.

Nobre, C.A.; Shukla, J.; Sellers, P.J. 1989. Impactos climáticos do desmatamento da Amazônia. Climanálise - Boletim de Monitoramento e Análise Climática, 4(9):44-55.

Oliveira, A.; Nobre, C.A. 1985. Meridional penetration of frontal system in south America and its relation to organized convection in the Amazon. Relatório Técnico INPE 3407 - PRE/676, $4 \mathrm{p}$.

Oliveira, A.P. de; Fitzjarrald, D.R. 1993. The Amazon river breeze and the local boundary layer: I - Observations. Boundary Layer Meteorology, 63(1-2):141-162.

Oltman, R. E. 1967. Reconnaissance investigations of the discharge and water quality of the Amazon. Atas do Simposio Sobre Biota Amazonica. 3:163-185.

Paiva, E.M.C.D. 1996. Regime de precipitação na Amazônia e sua relação com o desmatamento e temperatura da superficie no mar. Tese de Doutorado, Universidade Federal do Rio Grande do Sul, Porto Alegre, Rio Grande do Sul, p. 297.

Paiva, E.M.C.D.; Clarke, R.T. 1995. Time trends in rainfall records in Amazonia. Bulletin of American Meteorological Society, 76(11):2203-2209.

Rao, V.B.; Cavalcanti, I.F.A.; Hada, K. Annual variation of rainfall over Brazil and water vapour characteristics over South America. Journal of Geophysical Research, 101(D21):26539-26551.

Richey, J.E.; Nobre, C.; Deser, C. 1989. Amazon river discharge and climate variability: 1903 to 1985. Science, 246:101-103.

Rocha, E.J.P da. 1991, Balanço de Umidade na Amazônia durante o Fluamazon. Dissertação de Mestrado, Departamento de Meteorologia, Universidade de São Paulo, São Paulo, São Paulo, p. 121.

Rocha, H.R. DA; Nobre, C.A.; Barros, M.C. 
1989. Variabilidade natural de longo prazo no ciclo hidrológico da Amazônica. Climanálise - Boletim de Monitoramento e Análise Climática, 4(12):36-42.

Rocha, H.R. da; Nobre, C.A.; Bonatti, J.P.; Wright, I.R. 1996. A vegetation-atmosphere interaction study for Amazonian deforestation using field data and a single column model. Quarterly Journal of Royal Meteorological Society, 122: 567-594.

Sa, L.D.A.; Viswanadham, Y.; Manzi, A.O. 1988. Energy flux partioning over the Amazon forest. Theoretical and Applied Climatology, 39(1): [-1116.

Salati, E.; Dall'Olio, A.; Matsui, E.; Gat, J.R, 1979. Recycling of water in the Amazon basin: an isotopic study. Water Resource Research, 15(5):1250-1258.

Salati, E.; Marques, J. 1984. Climatology of the Amazon region. In: Sioli, H. (ed). The Amazon - Limnology and landscape ecology of a mighty tropical river and its basin. Dr. W. Junk Publishers, Bonn, Alemanha, p. 85-126.

Salati, E.; Nobre, C.A. 1991. Possible climatic impacts of tropical deforestation. Climatic Change, 19(1-2):177-196.

Salati, E.; Vose, P. B. 1984. Amazon Basin: a system in equilibrium. Science, 225(4658):129-138.

Santos, I.A.1986. Variabilidade da circulação de verão da alta troposfer a na América do Sul. Dissertaçào de Mestrado, Universidade de São Paulo, São Paulo, São Paulo, p. 95.

Shuttleworth, W.J. 1988. Evaporation from Amazonian rain forest. Preceedings of Royal Society of London, série B, 233(1272):321-346.
Shuttleworth, W.J.; Gash, J.H.C.; Lloyd, C.R.; Moore, C.J.; Roberts, J.M.; Molion, L.C.B.; Nobre, C.A.; SÁ, L.D. de A.; Marques Filho, A.O.; Fisch, G.; Januário, M.; Fattori. A.P.; Ribeiro, M.N.G.; Cabral, O.M.R. 1987. Amazonian Evaporation. Revista Brasileira de Meteorologia, 2(1):179-191.

Souza, P.F.S. 1991. Variabilidade espacial e temporal das componentes atmosféricas do ciclo hidrológico da Amazónia, durante Experimento Meteorológico ABLE $2 B$. Dissertação de Mestrado, Instituto Nacional de Pesquisas da Amazónia, São José dos Campos, São Paulo, p. 82.

Tardy, Y.; Mortatti, J.; Ribeiro, A.; Victoria, R.; Probst, J. 1994. Fluctuations de la pluviosité de l'écoulement et de la temperature sur le bassin de l'Amazone et oscillations du climat global au cours du siecle écoule. Cahier Recherches Scientifiques - Paris, 318 (II):955-960.

Villa Nova, N.A.; Salati, E.; Matsui, E. 1976. Estimativa da evapotranspiração na Bacia Amazônica. Acta Amazonica, 6(2):215-228.

Viswanadham, Y; Molion, L.C.B.; Manzi, A.O.; SA, L.D.A.; Silva Filho, V.P. 1990. Micrometeorological measurements in Amazon forest during GTE/ABLE 2 A mission. Journal of Geophysical Research, 95(D9):13669-13682.

Wright, I.R.; Gash, J.H.C.; Rocha, H.R.; Shuttleworth, W.J.; Nobre, C.A.; Maitelli, G.T.; Zamparoni, C.A.G.P.; Carvalho, P.R.A. 1992. Dry season micrometeorology of central amazonian ranchland. Quarterly Jounal of Royal Meteorological Society, 118(508):1083-1009. 